\title{
Efforts into Establishing A Moral And Ethical Culture In Public Administration - Kenya: The Missing Link
}

\author{
Dr. Purity K. Gitonga \\ Head of Education, Training And Public Awareness Ethics and Anti-Corruption Commission \\ Kenya \\ pkgitonga@yahoo.com
}

\begin{abstract}
Public officers occupy positions of authority and trust and control enormous public resources. They also regulate many socio-economic and political activities. However, the public sector in Kenya has in the recent past been discredited for apathy, laxity, inefficiency, uncivility, wastefulness and unacceptable conduct that greatly impede access to and delivery of public services. The high perception of corruption prevalence in the public service has been costly for Kenya. This has led to loss of public trust and confidence in public service. For this reason, the Kenya government has put in place a multi-layered approach to combat the corrupt and unethical culture in the Public administration. The various approaches put in place bear the fact that corrupt and unethical conduct is both a systemic and personal problem. The paper presents on the various initiatives undertaken by the government in the recent years to institutionalize a culture of ethics and integrity in public administration and seeks to discuss on the missing link. The paper is divided into four sections. The first section highlights the meaning of terms and the relationships thereof. The second part delves into the various efforts undertaken by the government to create a moral and ethical culture in public service and highlights the weaknesses and insufficiency of codes of conduct and partnerships and collaborations and legislating on ethical issues. It notes that as much as such great measures have been put in place, curbing corruption and unethical practices stubbornly remain entrenched in public administration; thus the need to concentrate on two other areas of concern: strengthening leadership capabilities with special reference to leader self- efficacy that the writer considers to be the missing link. The theoretical framework will be based on Social Learning Theory, Social Cognitive theory and Self- Efficacy Theory. Data for this study were collected from academic books, scientific research papers, business journals as well as academic internet sources.
\end{abstract}

Key words: Culture; Ethics; Public administration; Moral values; Corruption; Self-efficacy; Ethical leadership; Public officer; State officer

\section{Introduction}

The hallmark of an ethical, high performing public service is the quality, accessibility and affordability of its services offered in an impartial, effective, prompt, responsive and equitable manner; solely acting in public interest without consideration of private interests; avoiding wastage and extravagance in expenditure. Moreover, public officers are expected to be accountable, efficient and effective and uphold high standards of integrity and professionalism without which they jeopardize public trust and confidence in government. Unfortunately, there has been a gap between public expectations and service delivery. 
A Report on Fostering Ethics and Integrity in Public Service (October, 2015) confirms existence of integrity and ethical lapses in the service. Examples of such ethical lapses include: wastefulness, misappropriation of fund, abuse of office, irregular recruitment, selective and unfair promotions, selective application of the law, delays in service provision, falsification of documents, stealing, absconding of duty, lateness, bribery, nepotism and tribalism in the discharge of public duty. These practices greatly impede access to and delivery of public services. The 2016/2017 Evaluation Report on Public Service Compliance with Values and Principles in Article 10 and 232 of the Constitution indicated that the Ministries and State Departments scored a mere 37.3 per cent on Thematic Area 8 on service delivery: performance and compliance.

In the recent report released by Transparency International (TI) on Corruption Perception Index (2017), Kenya had made dismal improvement in the fight against corruption. According to the TI Corruption Perception Index, Kenya scored 28 points out of a possible 100 lower than the combined average score for Africa which was 32 points. Kenya was ranked position 143 out of 180 . The high perception of prevalence of corruption in the country has not reflected well for the public service. Of course there are questions as to whether the rampant corruption reported is real, a perception, bad press or whether it is a question of increased awareness and freedom of speech and reporting. Unfortunately, the world is driven by perception and this has led to loss of public trust and confidence in public service. For this reason, the Kenya government has put into place to date a multi-layered approach to combat the corrupt and unethical culture in Public administration. These include: public service reforms, legislative frameworks, technological interventions, development of policies, codes of conduct and ethics, issuance of circulars and instructions and setting up of institutions responsible for ethics and anti-corruption matters.

However, the continued occurrence of integrity and ethical malpractices despite the existence of stringent legal provisions raise fundamental questions as to whether legislating integrity and ethical conduct alone is a panacea to ethical and moral conduct in the Public Service. While the status remains, and the fight against corruption and unethical conduct drags on, the need to employ other strategies cannot be challenged.

\section{Definition of terms}

According to the African Charter on Values and Principles of Public Service and Administration, the term Administration refers to any institution or organization at the continental, regional and national and sub-national levels that applies the public policies or undertakes public service duties, while Public Service means' any service or public interest activity that is under the authority of the administration.

Corruption is one of the most serious unethical practices that undermine the trust and confidence of public officials. Corruption is generally defined as 'the abuse of entrusted power for personal gain or for the benefit of a group to which one owes allegiance. Nye (1999) defines corruption in the broader and more operational sense as that 'behaviour which deviates from the formal duties of a public role because of private regarding (personal, close family, private clique) pecuniary or status gain or violates the rules against the exercise of certain types of private reading influence. The Oxford Dictionary defines corruption as: dishonesty, use of 
bribery, immoral, wicked behavior, something that is made unreliable by errors or alteration. Whatever the definition, it can be said that in a corrupt act; the course of actions is not transparent, the law is not observed, there is a party that gains though unfair means and a party that loses or is disadvantaged; personal interest override common interests. The mere fact that both the payer and the recipient of bribes of any corrupt deal want to keep their behaviour secret shows that such behaviour is generally considered to be improper, wrong, illegal, 'sinful' and unacceptable. It is a problem to be solved not only through legislation and systemic approaches but by means of personal 'reform'. Unfortunately, behind every corrupt deal there is a professional.

Ethics and morals relate to "right" and "wrong" conduct. While they are sometimes used interchangeably, Ethics refer to a set of rules provided by an external source while Morals refer to an individual's own principles regarding right and wrong behavior. Ethics reflects beliefs about what is good, right, proper and just versus what is bad, wrong and unjust in terms of human behaviour. As with corruption, central to the concept of ethics are attitudes, standards and systems of value which have been internalized in the civil servant. Personal ethics form the moral foundation on which people build their lives. Ethics, at whatever level (individual, organizational and professional), directs how people should conduct themselves; assist in decision making and the actions to be taken in relation to others; in problem solving and ability for determining "right" versus "wrong". It tells the world the values that the individual or organization stands for, and challenges the individual or organization to live up to those values.

Culture refers to the outlook, attitudes, values, goals and practices shared by a group, organization or society. It is the way things are done in a particular set up. The culture of an organization, or any group of individuals that share a common identity, is a reflection of the values and beliefs of the leaders. As Butcher (1987) noted, ethical behavior and leadership are intertwined and inseparable.

\section{Efforts by Kenya Government to institutionalize a culture of ethics and integrity in public administration \\ Public service reform initiatives}

The Government of Kenya has in the last 20 years undertaken a series of public sector reforms in efforts to transform the culture and attitude of public service employees, improve the quality and efficiency of public service delivery and enhance the capacity of public service leadership and management. These include: employee rationalization; structural adjustment Programme, Results based management; the Rapid Results Initiative; the Results Orientation Approach (2006 -2008), the Public Sector Reforms (2009) and the Kenya Economic Blueprint (Vision 2030), review and harmonization of public sector wages and the devolution of services; signing of self-declaration forms by persons seeking elective posts or appointment into government offices, vetting of candidates and signing of performance contracting framework. These reforms aimed at positively transforming the public service for better service delivery and counter any ethical deficiencies.

\section{Policy, Legal and Institutional Framework}

Other than the public sector reforms, Kenya have developed relatively elaborate policy, legal and institutional framework for the promotion of public service ethics and anti-corruption 
initiatives. The Constitution of Kenya promulgated in 2010 serve as the principal legal instrument for ethics and integrity in the country. Chapter Six on Leadership and Integrity spells out the fundamental principles that guide standards of conduct and responsibilities of state and public officers while the National and Public Service Values and Principles mentioned in Article 10 and 232 of the Constitution epitomize the expected behavior in the public service. This is a plus in the right direction, however, the spirit and letter of the Constitution is yet to impact on leadership.

Besides the Constitution, ethical conduct in the public service in Kenya is also governed by various legislations and policies such as the Public Officer Ethics Act, 2003, the AntiCorruption and Economic act, 2003; the Ethics and Anti-Corruption Act, 2011 (EACC Act); the Leadership and Integrity Act, 2012 (LIA); the Commission of Administrative Justice, Act, 2011; the Public Service Values and Principles Act, 2015; the Proceeds of Crime and AntiMoney Laundering Act, 2009 (POCAMLA); the Public Procurement and Asset Disposal Act, 2015 (PPAD) and the Public Financial Management Act, 2012; the Mutual Legal Assistance Act; the Bribery Act (2017), the National Values and Principles of Governance Policy Sessional Paper No, 8 of 2013; Vision 2030, Executive Order No. 6 of March 2015 on Ethics and Integrity in the Public Service, the Performance Contracting and Appraisal System and The Mwongozo - the Code of Governance for State Corporations among others. Through these pieces of legislation public officers are expected to act ethically and uphold integrity in the conduct of public affairs.

The Anti-Corruption and Economic Crimes Act (ACECA), 2003 is the principal legislation enacted to curb corruption in Kenya. ACECA defines corruption by identifying offences that constitute corruption in Kenya. The Act criminalizes bribery, fraud, abuse of office, extortion, conflict of interest, deceiving the principal, favoritism or discrimination, tax evasion, bid rigging, embezzlement and misappropriation of public funds among other offences. The Act provides for imprisonment and other penalties for breach of its provisions. Indeed many public officers have suffered imprisonment and fines for contravening the provisions of this Act. However, high levels of acquittals signal that reducing corruption through prosecution difficult.

The Public Officer Ethics Act (POEA), 2003 and the Leadership and Integrity Act, (LIA), 2012 form the principal legal instruments in governing matters of ethics and integrity in Kenya's public service. The two pieces of legislation provide for: a code of conduct and ethics and the declaration of income, assets and liabilities. The Leadership and Integrity Act provides for a Specific Leadership and Integrity Codes for State Officers, while the Public Officers Ethics Act provide for a general code of conduct for public officers.

\section{Codes of Conduct}

As noted in the preceding paragraphs, the government of Kenya has thoughtfully provided for the development and enforcement of codes of conduct and ethics as per the Public Officer Ethics Act and the Leadership and Integrity Act. The two Acts provide for obligations for state and public officers in relation to moral and ethical requirements, professionalism, gifts or benefits in kind, financial probity, transparency and accountability, avoidance of conflict of interest and wastage of public resources, wrongful or unlawful acquisition of property, maintenance of public confidence in the integrity of public office, political neutrality and use 
of official information among other provisions. In simple, the codes give guidance on what behaviour is appropriate and acceptable and assist in decision- making and the right thing to do, serve as reference for solving ethical dilemmas and safeguard the fundamental principles of Integrity. Personal integrity, trustworthiness and professionalism remain at the heart of all codifications of ethical conduct.

Efforts in the development of Codes of Conduct in Kenya can be said to be excellent, but how well are they known by the stakeholders and how well they are subscribed to and enforced remains to be seen. Pennington $(2004,1995)$ acknowledges that written codes and value statements are necessary, and have worked in some cases. But he categorically argues that written codes and value statements do not ensure integrity in word and deed because they have been routinely ignored while behavior that is at best, questionable becomes the order of the day. Whitton, (2001) too states that publishing a code of ethics by itself will not achieve much, while Tobah, (2017) states that codes of conduct have lost their potency unless they are properly enforced. 'A code of ethics means nothing to those who are not aware of it, it means little if it is not subscribed to; and it may have no significance if it is not enforced'.

\section{Declaration of wealth}

Both state and public officers are bound by POEA and LIA to declare their income, assets and liabilities at the time of entry into the service and on exit from the service. Failure to submit the declarations is a criminal offence which renders a non-compliant officer liable to, upon conviction, a fine not exceeding Sh1 million or imprisonment for a term of not exceeding one year or both. Evaluation Reports by the Public Service Commission 2011-2013, 2014-2015 indicated that in the compliance levels stood at 95per cent. However, debates abound as to whether the declaration of income, assets and liabilities is not just a shamble. TI- Kenya Executive Director Samuel Kimeu said "Wealth Declaration is never taken seriously;" so devalued are wealth declarations that despite the legal requirement and the consequences of failure to declare, not even the independent Electoral and Boundaries Commission (IEBC) gave a thought to it when clearing candidates for the last General Election" The challenge with wealth declaration is that there is no clear provisions for auditing of the declaration reports.

\section{Institutional Framework}

The enactment of laws has been accompanied by establishment of institutions with specific mandate to combat corruption and unethical conduct. These include: the Ethics and Anti-Corruption Commission, Special Magistrates Anti-corruption Courts, the Judiciary, Office of the Director of Public Prosecution, the National Anti-Corruption Steering Campaign Committee, the Assets and Recovery Agency and Financial Reporting Centre.

In 2003, the then President of Kenya launched the National Anti-Corruption Steering Campaign Committee with the aim of taking the fight against corruption beyond the law, crime and punishment. The campaign was to help attend to attitude and behavior change. The Ethics and Anti-Corruption Commission (EACC), Kenya's premier anti-corruption agency employs a four pronged strategy in the fight against corruption namely: law enforcement (investigations, asset tracking and asset recovery), Prevention, Public Education and Awareness Creation and the Promotion of Ethics, Integrity and Best Practices and development of Codes of conduct. The education strategy aims at raising consciousness about ethical norms and fostering and 
enlisting public support against corruption. Criticisms for failure to effectively prosecute highprofile cases involving senior public officials accused of misappropriation of public resources abound.

\section{Regional and International Instruments.}

International cooperation can help engender both the will and the capacity to fight corruption. For this reason, Kenya was the first country to sign and ratify the United Nations Convection Against Corruption, 2003; and was quick to domesticate the International Code of Conduct for Public Officials as per Chapter 111 of the African Charter on Values and Principles of Public Service and Administration through the Public Officers Ethics Act, 2003 and the Leadership and Integrity Act, 2012. Kenya is also a signatory of the African Union Convection on Preventing and combating Corruption (AUACPCC), and the International Code of Conduct for Public Officials. Indeed, this is another demonstration and commitment to the promotion of ethics and integrity.

\section{Partnerships and Coalition Building in Kenya}

The United Nations Convection Against Corruption under articles 5, 12, and 13 makes a case for involvement of public (government), private, civil society and other sectors in the fight against corruption. In Kenya, the linkages and partnership strategy is realized through the Multi Agency Team (MAT) approach and the Kenya Leadership and Integrity Forum (KLIF). MAT serves as a cooperation, coordination and collaboration center for all agencies that play a part in the investigations and prosecution of corruption, economic crime and other organized crimes. KLIF is a stakeholder forum comprised of State and Non- State actors. The multisectoral approach is a realization that governments cannot fight corruption and unethical practices alone. Like any other approach, the partnerships and coalition building against corruption in Kenya faces operational challenges of lack of adequate funding, inadequate support and commitment of the partners, mistrust, value mismatch, overlaps and 'conflict' between the mandates of the stakeholders.

\section{Discussion}

\section{Has there been Impact as a result of efforts made?}

It can be said that the efforts made by the government to institutionalize a moral and ethical culture in the public service has borne some fruit and made some positive impact in the delivery of public service. The Compliance Reports by the Public Service Commission and the Ethics and anti-corruption Commission indicate an increase in levels of awareness on ethics and integrity among public officers; increased levels of accountability, punishment of offenders, involvement of the private sector and citizen participation. Significant levels of adherence to Codes of conduct and ethics at national and County Governments have been recorded and high levels of compliance to declaration of income, assets and liabilities with (75 percent being the lowest level of compliance and 95 percent being highest level of compliance(2014 Report). 


\section{Challenges}

Institutionalizing a culture of integrity and ethical behavior has not been without challenges. Though the government has made commendable efforts in attempts to curtail unethical lapses, corruption and unethical practices remain a serious challenge to contend with. Increased levels of awareness have not quite translated to action. This can be attributed to the existence of a culture of instant gratification; the fact that corruption perpetrators keep on changing tact, lack of commitment and political goodwill. The National Ethics and Corruption Survey by EACC (2015) indicated that only 28.4 percent and 26.3 percent of Members of Parliament and Governors respectively demonstrated credible intent to tackle perceived causes and effects of corruption effectively. Though Kenya is highly legislated against corruption and unethical conduct with almost a score of 100 per cent, there exist gaps in law and weak enforcement. The anti-corruption legal environment is too complex, laws being scattered in a number of statutes, court injunctions and stay orders and possible conflict of laws that weaken the prosecution of corruption and unethical conduct. The various legislations have strengthened public systems but the questions that linger on are: can we adequately legislate on issues of moral conduct? Can ethical mattes be dealt with as criminal offences? This paper proposes a paradigm shift in ethical and anti-corruption approaches

\section{The role of leadership in determining ethical behaviour}

This paper is based on the premise that strengthening leader efficacy can further help in institutionalizing an ethical culture in public service. This proposition is based on the fact that both theory and research suggest that leaders set the ethical tone of organizations and they cannot shrink from their obligations to set a moral example for those they lead (Murphy and Enderle, 1995).

Several factors influence member's perception of an organization's norms and expectations but it is the organization's leaders who play the primary role in creating climates regarding ethics. The behavior of leaders and the kind of values embodied in their actions reflect the direction of business ethics. Their adherence to ethics or their violation of the ethics send signals to the organization of what norms should be followed and what values are to be aspired (Philips 2004, Gitonga, 2012). Leaders whose personal ethics and values do not support the organization's values may signal other members of the organization that the company's values are not important. Leaders set the ethical tone of organizations by role modeling, through visible actions, communicating ethical standards, rewarding ethical conduct, punishing unethical conduct to reinforce normatively appropriate conduct and decision-making" (Trevino, Hartman and Brown, 2000; Brown, Trevino and Harrison, 2005, p.120).

There are several theoretical explanations for how leaders influence ethical and unethical behaviours- the Social Learning theory (Bandura, 1977; the Social Exchange Theory and the Cognitive Moral Development Theory (Kohlberg (1969). This paper focuses on the Social Learning Theory that states that, leaders influence ethical and unethical conduct of followers by way of modeling. Modeling is acknowledged to be one of the most powerful means of transmitting values, attitudes and behaviours. Employees learn what to do, as well as what not to do by observing their leaders behavior and its consequences. Leaders are likely to be models by virtue of their assigned role, their status and success in the organization and their power to affect the behavior and outcomes of followers. 
The Social Exchange perspective suggests that subordinates are likely to reciprocate with positive behaviour when they see their leaders are involved in relationships that are based on admiration and trust. The Cognitive Moral Development Theory focuses on how individuals reason through ethical dilemmas and how they decide what is right.

\section{Self-efficacy model}

Self- efficacy has been defined as beliefs in one's capabilities to mobilize the motivation, cognitive resources and course of action needed to meet given situational demands. Selfefficacy, the belief that one has the personal capabilities and resources to meet the demands of a specific task, was first introduced by Bandura (1997). Self-efficacy is said to be determined by four main aspects: personal experiences, perceived ability- observational learning, social persuasion (feedback) and reflection. Self-efficacy is used in two different ways: as 'task selfefficacy' denoting the perceived ability to perform a particular behaviour and as 'coping selfefficacy' denoting the ability to prevent, control, or cope with potential difficulties that might be encountered when engaged in a particular performance. Individuals can have high selfefficacy or low self-efficacy. Individuals with high self-efficacy have confidence in their ability to overcome obstacles and to perform well (Bandura, 1997)

\section{Research findings on self-efficacy}

Research based on self-efficacy theory has found that personal efficacy influences the goals people choose, their aspirations, how much effort they will exert on a given task and how long they will persist in the face of difficulties, obstacles and disappointments (Maurer, 2001). Also findings have linked self-efficacy with whether a person experiences self-hindering or self-aiding thought patterns, how well a person responds to taxing and threatening circumstances and how resilient a person is when faced with adversity and setbacks (Bandura, 1997). Reviewing the results of several studies, Bandura (1997) described effective individuals as people who are motivated, highly committed, resilient to adversity, goal-oriented, and able to think clearly even under pressure or in stressing conditions and able to solve problems in an efficient, practical, and quick way.

Over the last two decades, research findings have demonstrated a strong positive relationship between self-efficacy and work-related performance. A recent review and metaanalysis by Stajkovic and Luthans (1998a) found that $28 \%$ of performance improvement could be attributed to an employee's task-specific confidence. Hannah, Woolfolk, \& Lord (in press) and Hannah \& Luthans (2008) have recently proposed that positive psychological states such as efficacy directly promote effective leader engagement, flexibility and adaptability across the varying challenges characterizing complex organizational contexts. This is because higher levels of self-efficacy provide the internal guidance and drive to create the agency needed to pursue challenging tasks and opportunities successfully (Carver and Scheier, 1998; Cropanzano et al., 993; Lord and Brown, 2004; Mischel and Shoda, 1998; Shamir et al., 1993). In sum, efficacious individuals are motivated, persistent, goal oriented, resilient, and clear thinkers under pressure (Maurer, 2001). 


\section{Self-efficacy and leadership}

A leader's belief in his or her ability to perform across variety of situations plays an important role in his or her effectiveness. Mosterova, J., Prochazka, J., Vaculik, M. and Smutny, P. (2015) state that there're many leaders in management or in political arena who are particularly successful in the leadership roles. They argue that the important contributor to their success might be their beliefs in their capacity to perform a job or particular task, in other words, their self- efficacy. Leaders with greater general self-efficacy are effective because they are inclined to expend greater efforts to fulfil their roles across all situations and to preserve longer when faced with difficulties. A study by Kane, Zaccaro, Tremble and Masuda (2002) demonstrated that leaders with high leadership self- efficacy set higher goals and had better task strategies which in turn led to better group performance. Wisner (2011) found that a leaders' leadership self- efficacy had a significant effect on the efficacies of his or her followers, which in turn resulted in higher performance of a group. While Bandura asserted that high levels of efficacy seem to be associated with higher levels of performance on all types of tasks in many different realms. This is in effect associated with the influence which efficacy has on personal choice. Chemers (1997) too established that leader's low leadership selfefficacy affects their ability to handle challenging tasks and solve a problem. Therefore they fail to complete their tasks. Thus, leaders with low leadership self- efficacy affect their performance and in turn performance of their followers.

Given that leadership is about social influence calling for not only technical, tactical, operational and strategic skills but also interpersonal and intrapersonal skills and that leadership roles in organizations are becoming increasingly broad, complex and demanding, high self - efficacy of the executive leaders may be a valuable resource for organizations.

This paper therefore presents the view that public service needs leadership that has high leader self-efficacy because such leaders are effective in that they are inclined to expend greater efforts to fulfil their roles across situations; they transfer their efficacy to followers, they set higher goals and have the commitment and belief and motivation to do that which they choose to do and they persevere longer when faced with difficulties.

Since efficacy has influence of the choices leaders make and the course of action they take, it is presumed in this paper that leaders with high self-efficacy can belief in their ability to fight corruption and choose courses of action or strategies that help pursue such a task. This calls for leader's belief in their ability to bring the desired change and for individual officers to make choices to act and behave morally in the course of duty.

\section{Figure 1. Conceptual Framework on factors that influence self-efficacy in relation to} Leader effectiveness

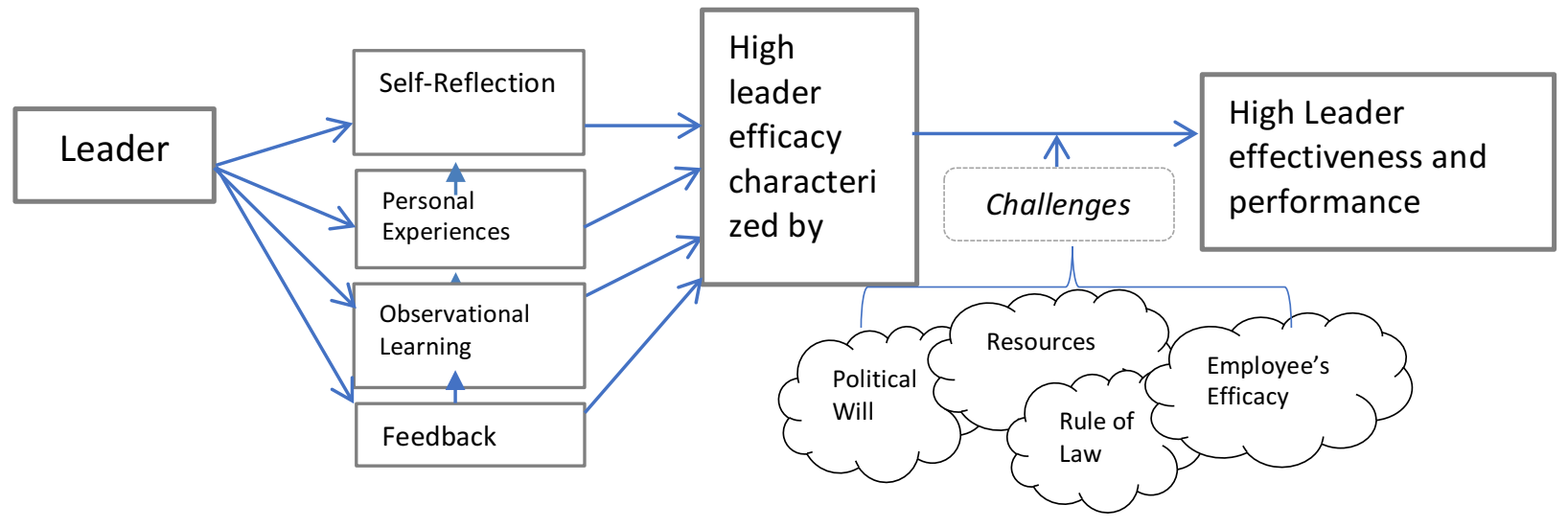


*The figure shows that the development of a leader's self-efficacy is influenced by personal experiences, perceived ability, observations and feedback from social settings. High leader self-efficacy in turn influences a leader's effectiveness and performance. However, there are factors that impede the relationship.

\section{Conclusion}

Affecting corruption and unethical conduct is a long-term process calling for multi-pronged approach and sustained effort over time. As discussed in the paper, it requires a legal system that is fair, transparent, and able to deliver justice; independent and empowered anti-corruption and ethics bodies; comprehensive policies, a credible and enforceable code of conduct and leadership that is committed to set the right example at personal and professional level. It demands a social system that presupposes equality. Political will, determination and financial support. It expects moral and ethical training from family and education system.

As stated in the paper, the world needs 'complimentary strategies' for the fight against corruption and unethical conduct to be effective in the current milieu. What 'complimentary strategies' does the world need to tackle unethical practices and forms of corruption at the institutional level? Leaders that are committed and believes in their capability to motivate and mobilize the resources and strategies needed to perform across situations even when faced with difficulties. Individuals who can influence and take action in preventing corruptive behavior are also needed.

Mr. Alexander Solzhenitsyn, a renowned Russian novelist who won the Nobel Prize for Literature in 1970 once said that; "Even the most rational approach to ethics is defenseless if there isn't the will to do what is right." An anonymous writer said "I often wonder whether we do not rest our hopes too much upon constitutions, upon laws and upon courts. These are false hopes. Integrity lies in the hearts of men and women; when it dies there, no constitution, no law, no court can save it; no constitution, no law, no court can even do."

\section{References}

Anti-Corruption and Economic Crimes Act, 2003

Anthony Makrydemetres. (2002). Dealing with ethical dilemmas in public administration: the 'ALIR' imperatives of ethical reasoning)

Brown, Trevino and Harrison (2005)

Chemers, M.M. (1997). An integrative theory of leadership. Mahwah, NJ: Lawrence Erlbaum associates

Ethics and Anti-Corruption Commission. National ethics and corruption survey 2015

Ethics and integrity training manual for senior officers in the public service 2016

Evaluation report for the year 2016/2017 on public service compliance with the values and principles in articles 10 and 231 of the constitution

Evaluation report for the year 2014/2015 on public service compliance with the values and principles in articles 10 and 231 of the constitution

Executive Order No.6 of March 2015 (Ethics and Integrity in the Public Service)

Gitonga, P. K. (2012). The relationship between emotional intelligence and leader effectiveness. Dissertation, University of Nairobi. 
Kane, T. D., Zaccaro, S. J., Tremble, T. T., Jr., \& Masuda, A. D. (2002). An examination of the leader's regulation of groups. Small Group Research 33, 65-120.

Leadership and Integrity Act, 2012

Michael, J. McCornick; Jes'us Tanguma; Anita, Sohn Lopez-Forment (2002). Extending Self Efficacy Theory to Leadership: A review and Empirical. Test Journal of Leadership Education. Volume1, Issue 2-Winter.

Mainga, P, J. (20112). Factors influencing adoption of ethical behaviour in selected public institutions in Nairobi County.

Maurer, T.J. (2001). Career relevant learning and development, work age and beliefs about self-efficacy for development. Journal of applied psychology 50:292-295

Mosterova, J., Prochazka, J., Vaculik, M. and Smutny, P. (2015). Relationship between SelfEfficacy Transformational leadership and leader effectiveness. Journal of advanced management science Vol 3, No.2.

Mwongozo: The Code of governance for state corporations

Nye, J,S. (1967).Corruption and political development: a cost benefit analysis, American political science review, LX1, No.2, 416

Philips, S. (2004). Ethics and a manager's obligation under stakeholder theory. Ivey Business Journal online, 68(4)1-4

Public Finance Management Act 2012

Ronald Berenbeim how effective are corporate codes in combating corruption? Paper presented during the 9th International Anti-Corruption conference

Randy Pennington, (2004). From Ethics to Integrity: How to make doing what is right a way of life.

The Kenya Constitution, 2010

The Public Officers Ethics Act, 2003

Tobah, B. (2017). Network for business sustainability. Downloaded on 4/2/2018

Wisner, M. D. (2011). Psychological strengths as predictors of effective student leadership. Christian Higher Education 10(3-4). 353-375.

Whitton, H. (2001). Implementing effective ethics standards in government and the civil service; Transparency International.

Whitton, H. 92007). Developing the ethical competence of public officials- a capacity building approach. 